\title{
FAST PROTONIC CONDUCTION IN PHOSPHATE GLASSES
}

\author{
YOSHIHIRO ABE \\ College of Engineering, Chubu University, \\ Matsumoto-cho, Kasugai-shi, Aichi, 487-8501 Japan
}

The description in text books of electrical conduction in glasses has been so far restricted to two types, that is, ionic conduction due to monovalent ions such as $\mathrm{Na}^{+}$ and $\mathrm{Ag}^{+}$, and electronic conduction. No chapter concerning with "protonic conduction in glasses" has appeared in text books. For a long time, protons (hydrogen ions) in glasses have been believed by many researchers to be almost immobile.' However, we assert that it is true for $\mathrm{SiO}_{2}$ glasses in which all protons are hydrogen-bonding free, but not true for many glasses containing non-bridging oxygen ions in which some protons are hydrogen-bonded. We have found that the mobility of protons in oxide glasses increases markedly with increasing strength of hydrogen bonding, i.e., with decreasing peak wavenumber ( $v_{\mathrm{OH}}$ ) of IR absorption band due to $\mathrm{O}-\mathrm{H}$ stretching vibration, and found that $\mathrm{MO}-\mathrm{P}_{2} \mathrm{O}_{5}$ glasses $(\mathrm{M}=$ alkaline earth metal $)$ without alkali ions and with a small amount of protons show high electrical conductivities due to protons. Recently the chapter for protonic conduction in glasses has appeared in a text book. ${ }^{2}$

Generally, the strengths of hydrogen-bonding in phosphates are higher than those in silicates and borates. This is one of the main reasons why phosphate glasses exhibit high protonic conductivities. It has been reported that crystalline hydrogen uranyl phosphate $\left(\mathrm{HUO}_{2} \mathrm{PO}_{4} 4 \mathrm{H}_{2} \mathrm{O}\right)$ gives high protonic conductivity and durability against water. ${ }^{3}$ However, uranium-containing materials are not applicable to commercial uses. The phosphate glassy films with high protonic conductivities which are reported here have a high potential use for solid electrolytes such as those for $\mathrm{H}_{2}-\mathrm{O}_{2}$ fuel cells and $\mathrm{H}_{2}$ gas sensors.

Our results are briefly summarized as follows

(1)Generally there exist two types of protons in oxide glasses. The IR absorption bands due to $\mathrm{O}-\mathrm{H}$ stretching appear at $v_{\mathrm{OH}} \approx 3600 \mathrm{~cm}^{-1}$ (band-1, free from hydrogen 
bonding) and $v_{\mathrm{OH}} \approx 2900 \mathrm{~cm}^{-1}$ (band-2, strongly hydrogen-bonded) which shift depending on glass structure and compositions. (It has been known that glasses containing non-bridging oxygens have band-2.). ${ }^{4}$

We found for the former ones to be "immobile protons" (or less mobile) and for the latter ones to be "mobile protons". The electrical carriers of alkaline-earth phosphate glasses without alkalies have been proved to be protons in the glasses. ${ }^{6}$

(2) The protonic conductivities $(\sigma, \mathrm{S} / \mathrm{cm})$ are not proportional to the concentration of the protons $\left(\left[\mathrm{H}^{+}\right], \mathrm{mol} / \mathrm{l}\right)$, but are proportional to the square of the concentration of carrier protons. ${ }^{5.7}$ Hence, the mobility is estimated to increase in proportion to the proton concentration.

$$
\left(\sigma=\mathbf{A}_{\mathbf{H}}\left[\mathbf{H}^{+}\right]^{2}\right)
$$

(3) The mobility term $\left(\mathrm{A}_{\mathrm{H}}\right)$ increases exponentially with the wavenumber of $v_{\mathrm{OH}}$; it increases approximately by one order with the shift of $100 \mathrm{~cm}^{-1}$ of $v_{\mathrm{OH}} \cdot{ }^{5}$

$$
\left(\log A_{\mathrm{H}}=-0.00970 v_{\mathrm{OH}}+17.1\right)
$$

(See Fig. 1)

Thus, it is surprising that the mobilities of the protons in $\mathrm{Ba}\left(\mathrm{PO}_{3}\right)_{2}$ glasses $\left(v_{\mathrm{OH}} \approx 2800\right.$ $\mathrm{cm}^{-1}$ ) are $10^{7} \sim 10^{8}$ times higher than those in $\mathrm{SiO}_{2}$ glasses $\left(\nu_{\mathrm{OH}} \approx 3650 \mathrm{~cm}^{-1}\right)$.

(4) The experimental activation energies for the protonic conduction $E_{H}$ which are obtained by Arrhenius plotting are expressed by the following equation. ${ }^{5}$

$\mathbf{E}_{\mathbf{H}}=\mathbf{E}_{0}+\mathbf{E}_{1} \quad\left(\mathrm{E}_{0}\right.$ is the value for $\left[\mathrm{H}^{+}\right]=1 \mathrm{~mol} / \mathrm{l}$; this is considered to be related to breaking of $\mathrm{O}-\mathrm{H}$ bond; $\mathrm{E}_{1}$ depends on the hopping distance or proton concentration )

$$
\begin{aligned}
& \mathbf{E}_{0}=\mathbf{B}_{0}+\mathbf{B}_{1} v_{\mathrm{OH}} \\
& \mathbf{E}_{1}=-\mathbf{B}_{2} \log \left[\mathbf{H}^{+}\right] \quad\left(\mathrm{B}_{0}, \mathrm{~B}_{1} \text {, and } \mathrm{B}_{2} \text { are const. }\right)
\end{aligned}
$$

(See Fig.2 \&3)

(5) Both protonic conductivity and activation energy of a given glass can be evaluated (by applying the above experimental equations) from the IR absorption spectrum of a given glass plate, without the electrical measuring.

(6) A common view so far accepted that the mobilities of protons in glasses are much lower than those of alkali ions has been disproved by our experiments and estimation. The mobilitiy of "mobile protons" in glasses is higher than that of alkali ions, and that of "immobile protons" is lower than that of alkali ions. ${ }^{8,9}$ (Fig. 4 indicates that in the the experimental concentration region the conductivity is 
determined by proton concentration but not by that of alkali ions.)

In contrast, it has been known for silica glass that the mobility of impurity protons in the glass is lower than that of impurity $\mathrm{Na}^{+}$ions. ${ }^{10}$

(7) Protonic conductivity increases markedly with the introduction of molecular water into glasses. The activation energy decreases with the molecular water content."

$$
\mathbf{E}_{\mathbf{H}}=\mathbf{E}_{0}-\mathbf{n} \log \left\{\left[\mathrm{H}^{+}\right]\left[\mathrm{H}_{2} \mathrm{O}\right]\right\}
$$

(8) Superprotonic glassy conductors $\left(10^{-2} \sim 10^{-4} \mathrm{~S} / \mathrm{cm}\right.$ at room temp. $)$ which contain a considerable amount of mobile protons and molecular water have been developed first by us using sol-gel processing. ${ }^{12}$ (See Fig.5) These materials have a high potential use for the solid electrolyte membranes of $\mathrm{H}_{2}-\mathrm{O}_{2}$ fuel cells and sensors for hydrogen gas and humidity. ${ }^{13}$

Thus, superprotonic glassy conductors have been developed for the phosphate systems containing molecular water but not for silicate systems without phosphorus. We believe that phosphate-containing materials are superior candidates for the superprotonic conductors which give room temperature conductivities of $10^{-2}$ to $10^{-4}$ $\mathrm{S} / \mathrm{cm}$. Another route for enhancement of the protonic conductivity of glasses has been tried by physical implantation of protons. ${ }^{14}$

\section{REFERENCES}

1. For example: F.M Ernsberger,, LNon-Cryst.Solids, 87, 408(1986);

L.Am.Ceram.Soc. 66, 747(1983); Phys.Chem.Glasses, 21 146(1980). ibid, 38 , 82(1997).

2. L.L. Hench \& J.K. West, "Principles of Electronic Ceramics"; (John Wiley \& Sons, New York, 1990), pp. 180-184.

3. M.G. Shilton, A.T., Howe, Mater.Res.Bull. 12, 701 (1977).

4. H. Scholze, Glastech.Ber. 32, 81(1959).

5. Y. Abe, H. Hosono, Y. Ohta, L.L. Hench, Phys. Rey., B38, 10166 (1988).

6. M. Kotama, K. Nakanishi, H. Hosono, Y. Abe, L.L. Hench, J. Electrochem. Soc. 138, 2928 (1991).

7. Y. Abe, H. Shimakawa, L.L. Hench, L Non-Cryst. Solids, 51, 357(1982).

H. Hosono, T. Kamae, Y. Abe, J.Am. Ceram. Soc. 72, 294(1989).

8. Y. Abe. M. Maeda, Phys. Chem. Glasses, 37, 176 (1996). 
9. Y. Abe, H.Hosono, O.Akita, L.L. Hench, L. Electrochem. Soc.,141, L64(1994).

10. R.H. Doremus, J. Electrochem. Soc. 115, 181(1968).

11. M. Nogami, Y. Abe, Phys. Rev. B. 55, 12108(1997).

12. Y. Abe, G. Li, M. Nogami, T. Kasuga, L.L. Hench, J.Electrochem. Soc. 143, 144(1996); M. Nogami, K. Miyamura, Y. Abe, ibid., 144, 2175(1997);

M. Nogami, R. Nagao, K. Makita, Y. Abe, Appl. Phys. Lett., 77, 1(1997).

13. K. Makita, M. Nogami, Y. Abe, L.Mater. Sci.Lett. 16, 550(1997).

G. Li, M. Nogami, Y. Abe, Solid State Jonics, 83, 209(1996).

M. Nogami, R. Nagao, K. Makita, Y. Abe, Appl. Phys. Lett., 77, 1(1997).

14. K. Kawamura, H. Hosono, H. Kawazoe, N. Matsunami, Y. Abe, L. Ceram. Soc. Japn, 104, 688(1996); H. Hosono, K. Kawamura, H. Kawazoe, N. Matsunami. Y. Abe, L.Appl. Phys. 81, 1296(1997).

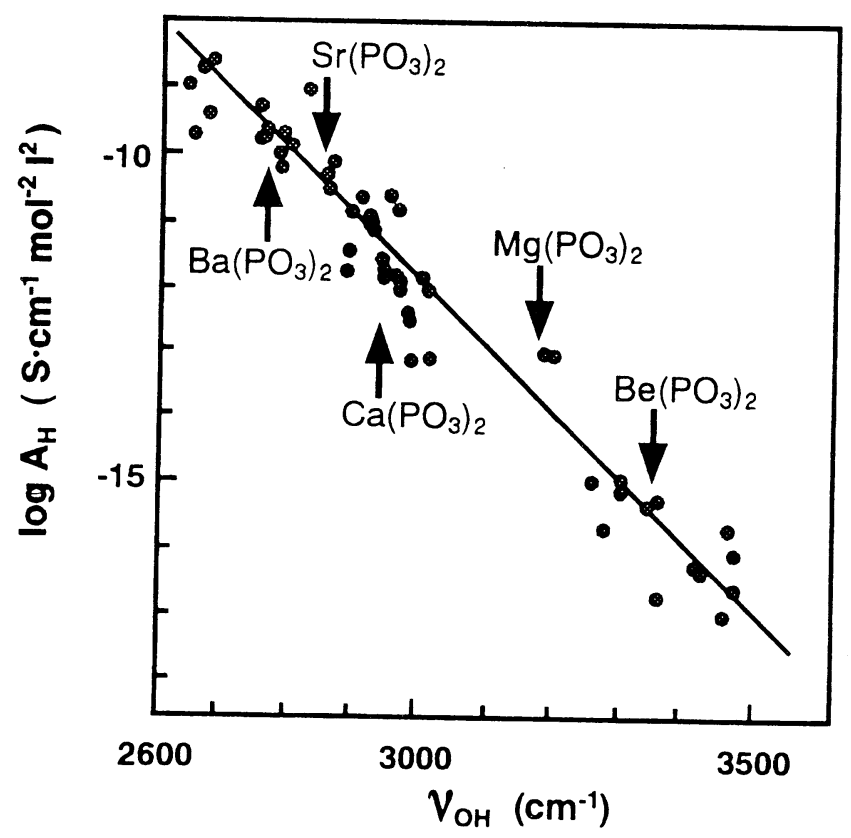

Fig. 1 Relation between $\mathrm{A}_{\mathrm{H}}$ and $\nu_{\mathrm{OH}}$. 


\section{$E=a+b \log \left[H^{+}\right]=E_{0}+E_{1}$}

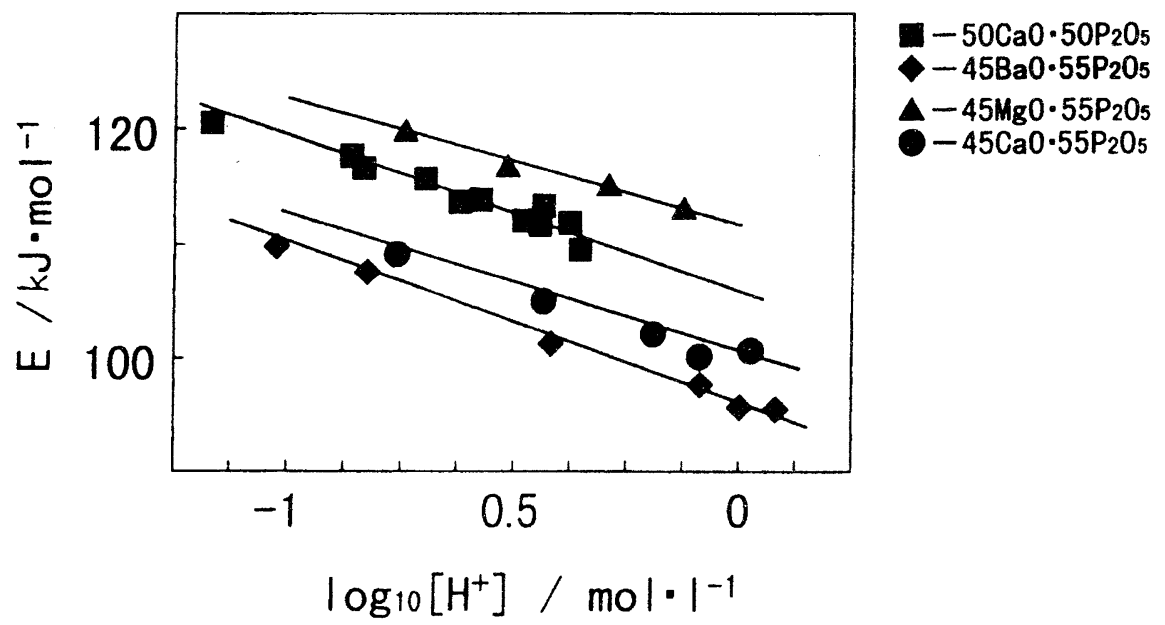

Fig.2 Dependence of experimental activation energy for protonic conduction (E) on proton concentration of various phosphate glasses.

$E_{H}=E_{0}+E_{1}$

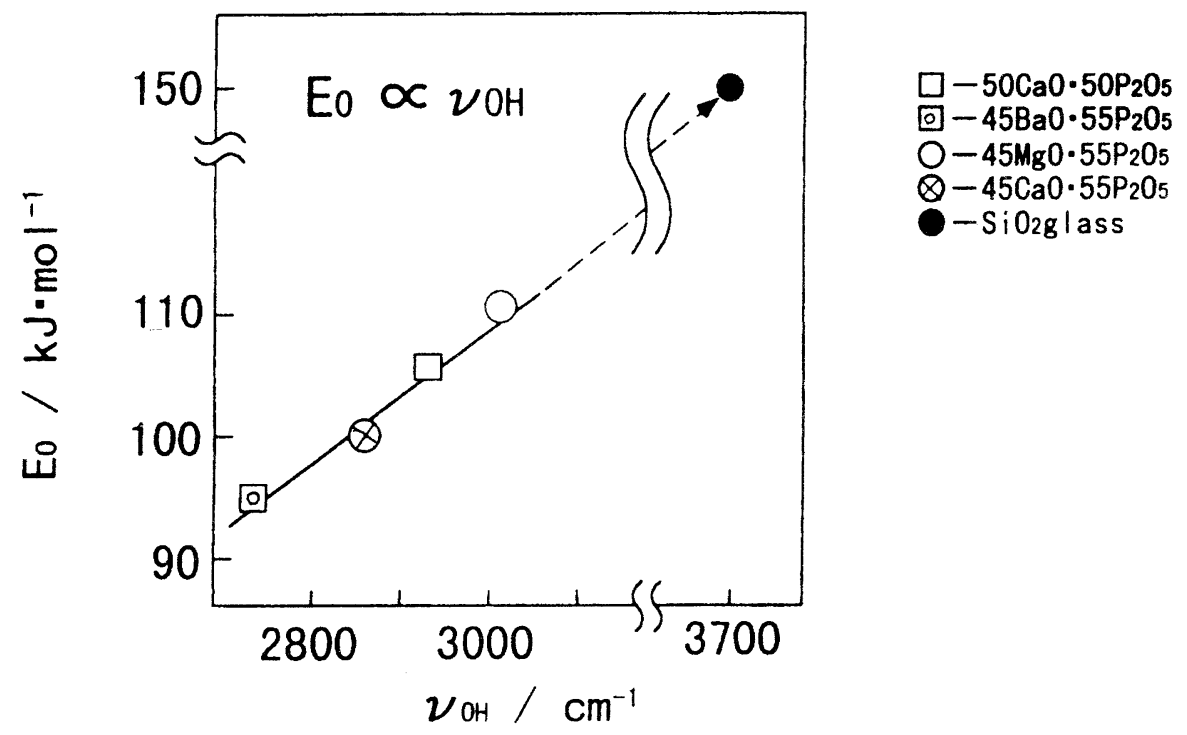

Fig.3 Relation between $\mathrm{E}_{0}$ and $v_{\mathrm{OH}}$ 


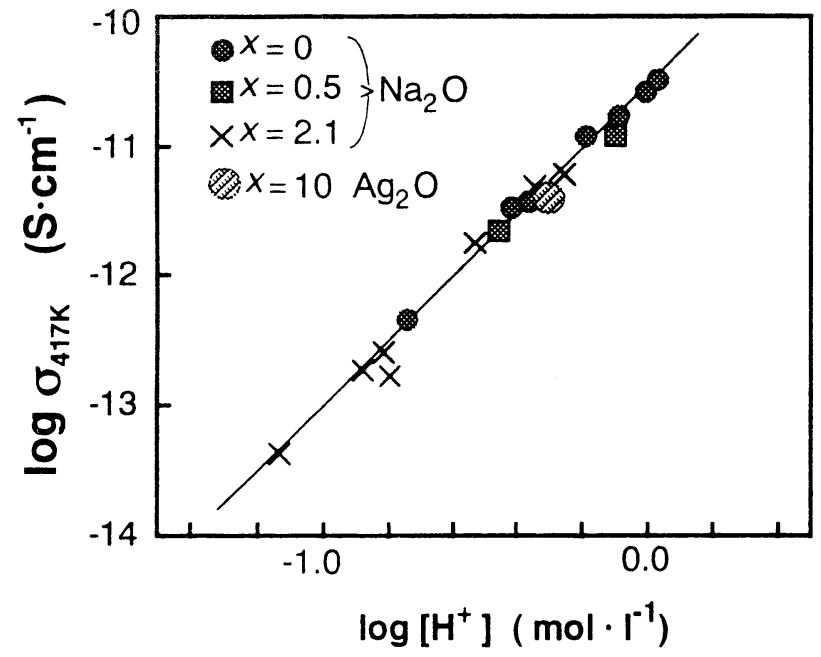

Fig.4 Effect of $\mathrm{Na}^{+}$or $\mathrm{Ag}^{*}$ ions on the de conductivitiy at $417 \mathrm{~K}\left(\mathrm{O}_{417}\right)$ due to protons of the glasses in the system of $100 \mathrm{CaOP}_{2} \mathrm{O}_{5}+\mathrm{xM}_{2} \mathrm{O}(\mathrm{M}=\mathrm{Na}$ or $\mathrm{Ag})$.

The conductivity is not changed by the addition of $\mathrm{M}$ ions, which indicates that mobility of protons of the glass is much higher than those of $\mathrm{M}^{+}$ions.

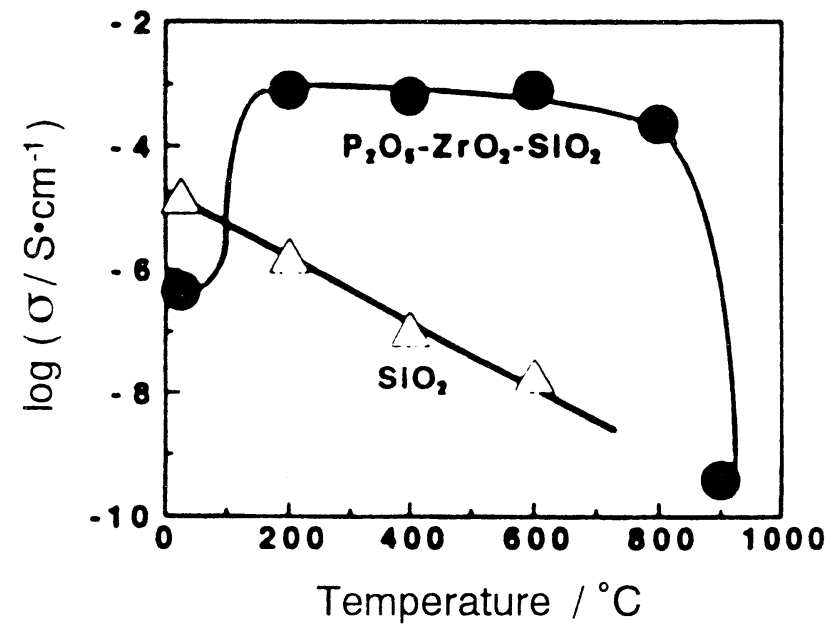

Fig.5 Conductivities ( at $30{ }^{\circ} \mathrm{C}, 50 \%$ relative humidity) of sol-gel derived $5 \mathrm{ZrO}_{2} 5 \mathrm{P}_{2} \mathrm{O}_{5} 90 \mathrm{SiO}_{2}$ and $\mathrm{SiO}_{2}$ glasses vs the drying temperature adopted for glass preparation. 